\title{
INATISMO MORAL
}

\author{
Matheus de Mesquita Silveira \\ Universidade de Caxias do Sul
}

\begin{abstract}
Resumo: Um aspecto inerente à vida social está no fato dela ser regida em suas diferentes esferas por regras de convivência. Contudo, não é qualquer forma de interação social que pode ser colocada dentro do escopo da moralidade. $O$ ponto central deste trabalho é encontrar um princípio de distinção entre as exigências que regem o comportamento moral daquelas presentes em outras formas de interação social. Indicarei no presente texto a possibilidade de uma abordagem evolucionista para esta questão. Defenderei que exigências morais possuem uma base emotiva e em que sentido este comportamento pode ser considerado inato. Em outras palavras, argumentarei em favor de que juízos morais são respostas emocionais circunscritas por emoções socialmente relevantes com base em mecanismos psicobiológicos de sociabilidade existentes devido à relação entre 0 ambiente e a estrutura natural de mamíferos sociais.
\end{abstract}

Palavras-chave: Moralidade. Naturalismo. Evolucionismo. Inatismo. Emoções.

Abstract: An inherent aspect of social life is that it is governed in its different spheres by rules of coexistence. However, it is not any form of social interaction that can be placed within the scope of morality. The central point of this work is to find a distinction between the demands that underlay moral behavior in relation to those present in other forms of social interaction. I will indicate in this article the possibility of an evolutionary approach to this question. I shall defend that moral demands have an emotional basis and in what sense this behavior can be understood as innate. In other words, I will argue in favor that moral judgments are emotional responses circumscribed by socially relevant emotions based on existing psychobiological mechanisms of sociability due to the relationship between the environment and the natural structure of social mammals.

Keywords: Morality. Naturalism. Evolutionism. Innatism. Emotions.

Grande parte da vida social de determinados mamíferos é regida por regras de convivência. O modo como o alimento será dividido, o volume e o tom de expressões vocais, a função que cada uma deverá desempenhar dentro do grupo e a forma como seus membros se cumprimentam, em suma, basicamente todas as suas interações durante as horas de vigília. Contudo, nem todos esses comportamentos pertencem à esfera da moralidade. $\mathrm{O}$ ponto em questão é encontrar um princípio de distinção entre as ações que regem o comportamento moral daquelas presentes em outras formas de interação social. Neste artigo me proponho a indicar a possibilidade de uma abordagem 
evolucionista para este problema. Defenderei num primeiro momento que exigências morais possuem uma base emotiva. Em outras palavras, aprovação e censura morais são respostas emocionais intensas circunscritas por emoções como culpa, vergonha, nojo e raiva; promovendo à manutenção da vida em grupo e a subsequente sobrevivência desses animais.

Numa perspectiva ampla, teóricos sentimentalistas e emotivistas defenderam em algum grau que as exigências morais estão baseadas num sistema de aprovação e desaprovação baseado em afetos. Uma ação é boa caso o sujeito sinta aprovação com relação a outro que a realiza, sendo que ela é ruim quando, nessas mesmas condições, sente-se desaprovação para com o seu autor. Greene coloca que:

conforme esta visão [...], a cooperação é tipicamente intuitiva. Nós não precisamos raciocinar mediante a lógica da cooperação em ordem de cooperar. Em vez disso, nós temos sentimentos que fazem esse raciocínio por nós ${ }^{1}$.

Os termos aprovação e desaprovação operam neste cenário como reações que agrupam dois tipos diferentes de emoções encontradas no comportamento moral. As do primeiro tipo são as reações emocionais positivas associadas ao elogio, como gratidão, estima e benevolência. Já no segundo estão presentes aquelas associadas à censura, como culpa, raiva, nojo e vergonha, sendo todas negativas.

Para constituírem a base da moralidade, considero que estas emoções devem emergir de maneiras específicas. Primeiramente, uma exigência não deve ser considerada como moral simplesmente por despertar alguma das respostas emocionais citadas acima de maneira isolada. Por exemplo, é comum o sentimento de dor e nojo ao ver que alguém cortou acidentalmente o dedo, mas daí não decorre que necessariamente se sentirá vergonha ou culpa com relação a este ato. Dado o aspecto social das relações morais, defenderei que as emoções adquirem uma natureza moral quando forem sentidas como resposta a interações socialmente relevantes, devendo possuir uma natureza intersubjetiva para que adquiram força normativa. Sendo assim, elas devem emergir a partir de mecanismos psicobiológicos de sociabilidade presente em animais de vida social complexa, podendo estar direcionadas tanto ao próprio sujeito quanto aos outros membros da comunidade.

Prinz (2008) atenta que mesmo juízos morais complexos estão relacionados à capacidade de experienciar emoções. Por exemplo, caso o sujeito faça algo errado e não sinta culpa, outros sentirão raiva dele por sua

${ }^{1}$ According to this view [...], cooperation is typically intuitive. We need not reason through the logic of cooperation in order to cooperate. Instead, we have feelings that do this thinking for us (GREENE, 2013, p.133, minha tradução). 
falta de remorso. $\mathrm{O}$ autor avança colocando nas emoções uma condição necessária para que um comportamento seja moralizado. Em outras palavras, para que se tenha uma atitude moral com relação a $\mathbf{X}$, deve-se ter a capacidade natural que pré-dispõe o sujeito a sentir a emoção auto-direcionada de culpa para com $\mathbf{X}$, assim como a raiva ou vergonha dirigida a terceiro quando eles fizerem $\mathbf{X}$.

Pesquisas na área da psicologia mostram que o comportamento moral está intimamente relacionado com emoções. Wheatley e Haidt (2005) hipnotizaram sujeitos para sentirem um leve nojo sempre que ouvissem uma palavra considerada neutra como, por exemplo, frequentemente ${ }^{2}$. Em seguida, eles entregaram aos participantes diversas histórias descrevendo sujeitos e pediram que fosse realizada uma avaliação moral dos mesmos. Em comparação com o grupo de controle, aqueles que foram hipnotizados fizeram avaliações morais significativamente mais negativas quando a palavra frequentemente estava na descrição, inclusive condenando sujeitos que foram descritos positivamente pelo grupo de controle.

Da mesma forma que a indução de emoções influencia numa avaliação de caráter, uma deficiência emocional resulta no que Cleckley (1941) denominou cegueira moral. Blair (1995) mostrou que psicopatas não conseguem estabelecer uma distinção entre normas morais e convencionais, argumentando que eles consideram a ambas como a mesma coisa. Pesquisas conduzidas por Patrick (1994) apresentaram que eles sofrem de profunda carência de emoções negativas, incluindo culpa e vergonha. A interpretação predominante é a de que a sua incapacidade de experienciar emoções socialmente relevantes os impede de estabelecer as relações de reciprocidade inerentes ao fenômeno da moralidade. Neste sentido, ainda que dotados de grande capacidade intelectual, psicopatas apresentam uma profunda incapacidade de apreender normas morais.

\footnotetext{
No entanto, o psicopata apresenta não só uma deficiência, mas aparentemente uma total ausência de auto-avaliação enquanto uma experiência real e comovente. Aqui está uma pessoa espetacular que usa todas as palavras que seriam usadas por alguém que compreende, e que poderia definir todas as palavras, mas que ainda é cego ao seu significado ${ }^{3}$ (CLECKLEY, 1941, p.351 minha tradução).
}

20 termo em inglês utilizado pela pesquisa em questão foi often.

3 Yet the psychopath shows not only a deficiency but apparently a total absence of self-appraisal as a real and moving experience. Here is the spectacle of a person who uses all the words that would be used by someone who understands, and who could define all the words but who still is blind to the meaning (CLECKLEY, 1941, p.351). 
As pesquisas mencionadas acima atestam à plausibilidade do argumento de que há uma ligação entre emoções e o modo como ações são moralmente aprovadas ou censuradas. Conforme Prinz (2008), alguém que está plenamente convencido de que determinada ação possa maximizar a felicidade da sua comunidade não precisa estar necessariamente convencido de que tal ato é moralmente bom. Por exemplo, tem-se o mito do bombardeio de Coventry $^{4}$ durante a Segunda Guerra, onde foi alegado que o governo britânico sabia do ataque nazista, mas optou por não evita-lo para não alertar os países do Eixo de que havia quebrado seus códigos militares. Da mesma forma, da aceitação de que uma ação poderá incorrer numa contradição prática ao ser universalizada, não decorre que ela seja considerada como moralmente ruim. Por outro lado, considere um sujeito que sinta raiva de outro ao este realizar determinada ação $\mathbf{X}$ e que, da mesma forma, sentiria culpa caso ele mesmo realizasse $\mathbf{X}$. Este sujeito provavelmente considera o comportamento $\mathbf{X}$ como moralmente censurável. Ele poderia rever sua posição ou até questionar sua postura posteriormente, mas daí não decorre que ele não moralizou esta conduta num primeiro momento. Dessa forma, ainda que se possa questionar se o conteúdo de $\mathbf{X}$ deva ser mesmo considerado como ruim, é inegável que uma condenação emocional ocorreu como resposta a $\mathbf{X}$ e o que seria modificado é a natureza da resposta emocional para com este comportamento.

Caso a hipótese de que o princípio de distinção entre relações sociais e morais possua uma fundamentação natural, então é preciso explicar tais comportamentos a partir de uma base evolutiva. Isso pode ser traduzido na pergunta pelo sentido em que o fenômeno moral pode ser considerado como inato. Note-se que esta hipótese não pode ser sustentada a partir do simples argumento de que certos animais estão instintivamente dispostos a agirem mediante regras sociais. Por exemplo, abelhas (Apis mellifera) apresentam comportamento altruísta, uma vez que tendem a morrer para defender suas colônias. Todavia, disso não decorre que elas ajam motivadas por uma norma ou exigência moral. Portanto, é preciso compreender em que sentido determinados animais de vida social complexa poderiam estar naturalmente inclinados a realizar exigências morais, considerando o elemento emocional presente em tal comportamento. Neste sentido, é preciso compreender o princípio que distingue o ato de seguir uma norma convencional de uma moral, a fim de diferenciar um comportamento mecânico de um legítimo interesse pelo bem-estar do grupo. O primeiro passo para realizar essa tarefa é entender o que significa inatismo.

${ }^{4}$ Coventry é uma cidade do distrito metropolitano do Reino Unido, sendo a oitava maior cidade da Inglaterra. 


\section{Comportamentos inatos}

A definição do conceito de inato pode ser bastante complexa. Têm-se comumente a ideia de que somente é possível falar em inatismo para casos como o de genes codificando proteínas, sendo que o mesmo não se aplicaria com relação a fenótipos ${ }^{5}$. Contudo, Prinz (2008) argumenta que esta relação é possível se investigarmos comportamentos sociais tanto sob o aspecto conceitual como experimental. Conceitualmente, a ideia central colocada por Cowie (1999) é a de que o fenótipo $\mathbf{X}$ é inato se for adquirido mediante mecanismos que são dedicados a $\mathbf{X}$, em oposição aos que evoluíram para desempenhar originalmente outra função. Ainda que esta seja uma definição simplificada, defendo que ela ganha força se definirmos comportamentos sociais inatos a partir de características operacionais.

Determinados comportamentos inatos possuem uma natureza bastante rígida, manifestando-se de maneira fixa e sendo consideravelmente imunes a mudanças. A dinâmica de grupo apresentada por abelhas reside nessa categoria. Michener (1974) sustenta que elas apresentam uma estrutura social rígida, não possuindo em sua natureza um espaço de manobra que as permitam agir de outra forma. Em outras palavras, o seu comportamento é impulsionado por uma programação genética simples. Nesse sentido, pode-se dizer que o engajamento social das abelhas se dá de forma rígida e não por uma legítima consideração pelo bem estar do grupo. Embora o comportamento de mamíferos sociais seja mais complexo, eles apresentam representações sensoriais deste tipo. Por exemplo, reações de ansiedade encontradas em canídeos na presença de sons altos ou a capacidade de primatas visualizarem a cor branca ao observar a neve.

Características fisiológicas sensíveis ao ambiente também podem ser consideradas inatas, ainda que possuam uma variação limitada. Um exemplo claro é o do gudião-azul (Thalassoma bifasciatum). De acordo com Marsh (2007), os membros dessa espécie de peixe tem seu gênero alterado em determinadas circunstâncias. Quando os machos do cardume morrem, a fêmea que possui o maior tamanho troca de gênero e assume o seu lugar. Ainda que as condições possam variar, uma das configurações possíveis de gênero será necessariamente selecionada.

Da mesma forma, no gudião-azul e em outros peixes hermafroditas onde transições de comportamento podem ocorrer em questão de minutos ou horas, parece provável que um circuito funcional do comportamento masculino está

5 A transmissão de fenótipos é utilizada nas ciências naturais para identificar um conjunto de características observáveis, estando associada à transmissão de padrões de comportamento, onde 0 fenótipo é o resultado de interações entre o genótipo e as influências ambientais. 
presente antes da mudança de gênero, um que consiste tanto do comportamento sexual de macho e fêmea sob o controle de diferentes entradas endógenas e exógenas. A inibição estrogênica pode, então, ser considerada como um modulador de comportamento em potencial, nesse caso suprimindo o típico comportamento sexual de machos. A diminuição da inibição, devido à mudança de sinais sensoriais derivados socialmente, poderia estimular a exposição do típico comportamento de $\operatorname{machos}^{6}$ (MARSH, 2007, p. 77 - minha tradução).

Existem também características inatas que apresentam grande flexibilidade, como o canto dos pássaros. De acordo com Kelley et al. (2008), o estorninho (Sturnus vulgaris) pode mimetizar o canto de inúmeras aves, possuindo uma vocalização sonora com características flexíveis. Este mecanismo o permite transmitir os cantos miméticos para várias gerações, mas as mesmas vocalizações não são necessariamente encontradas em toda a espécie. Conforme Hausberger et al. (1991), estorninhos introduzidos na Nova Zelândia no século XIX são mímicos proficientes, mas seu repertório não incluí o canto das diversas aves europeias inexistentes no continente. Contudo, o autor reporta que as espécimes europeias eram capazes de mimetizar as vocalizações ausentes no repertório das que habitam a Oceania.

A hipótese defendida é a de que há uma transmissão genética associada à capacidade inata de mimetizar e reproduzir o canto de outras aves. No entanto, o conteúdo transmitido pode variar entre diferentes grupos da mesma espécie. A capacidade mimética destes pássaros reside num mecanismo específico para aprender e imitar vocalizações e não num sistema geral de aprendizagem que engloba essa finalidade. O ponto ao qual chamo atenção é que, embora o conteúdo vocal mimetizado pelo estorninho-comum seja resultado do ambiente em que vive, ele é capaz de fazê-lo devido à existência de um dispositivo biológico inato que o torna apto a realizar essa tarefa. Características inatas desta natureza também podem ser encontrados em seres humanos. Por exemplo, Prinz (2008) ressalta a capacidade humana de abstrair protótipos perceptuais a partir da experiência e utilizá-los para uma subsequente categorização. Esta é considerada uma capacidade que possui grande flexibilidade e que evoluiu com este propósito específico.

\footnotetext{
${ }^{6}$ Similarly, in the bluehead wrasse and other sex-changing fishes where behavioral transitions can occur in minutes to hours, it appears likely that a functional male behavioral circuit is present prior to sex change, one that consists of both male and female sexual behavior under the control of different endogenous and exogenous inputs. Estrogenic inhibition could then be considered a potential modulator of behavior, in this case suppressing male-typical sexual behavior. Decreased inhibition, due to changing socially-derived sensory cues, could stimulate the male-typical behavior to be unmasked (MARSH, 2007, p. 77).
} 
Prinz (2008) defende que há três modos pelos quais um comportamento pode ser considerado inato. Essas três formas se referem a atributos comportamentais dotados de uma natureza rígida, qualidades fisiológicas sensíveis ao ambiente, embora com variação limitada e características flexíveis presentes devido à existência de um dispositivo biológico que evoluiu para essa função em particular. Contudo, o autor salienta que existem comportamentos que parecem inatos, porém constituem subprodutos de outras capacidades. Por exemplo, Cristol e Switzer (1999) relataram que corvos (Corvus brachyrbynchos) utilizam carros para quebrar nozes e se alimentarem. A sequência típica desse comportamento consiste em jogar a noz na faixa de segurança onde circulam automóveis, de modo que os veículos passem por cima do fruto e o quebrem. No momento em que o sinal fecha, eles voam até o local para comer os fragmentos. Esta não é em si uma capacidade inata destas aves, sendo adquirida mediante um sistema instintivo e geral de aprendizagem, por meio de um condicionamento operacional. Esta capacidade dos corvos é considerada análoga à encontrada em seres humanos quando aprendem a dirigir.

Pulgas (Siphonaptera pulicidae) de circo são capazes de realizar feitos notáveis, como participar de jogos de arremesso utilizando uma bola minúscula. Isso ocorre porque a bola é revestida com um produto nocivo que estes insetos rejeitam instintivamente. Portanto, quando entram em contato com o agente químico, elas são impelidas a se livrar da bola e jogá-la para outra pulga, repetindo o processo sucessivamente. Ao contrário dos corvos, esta dinâmica não tem como base um sistema instintivo geral de aprendizagem, mas uma adaptação evolutiva cuja finalidade específica é evitar substâncias químicas nocivas. Ainda que apresentem proezas notáveis dentro de um ambiente controlado, as pulgas não o fazem intencionalmente. Nesse sentido, o comportamento de jogar bola umas para as outras não é inato, mas sim sua capacidade de repelir certas substâncias químicas.

Para que o fenômeno moral seja considerado inato, Prinz (2008) argumenta que ele precisa apresentar uma estrutura inflexível com elementos universais rígidos. Em outras palavras, deve possuir características semelhantes ao comportamento social das abelhas. Contudo, essa visão é excessivamente reducionista e os exemplos acima mostram que há mecanismos comportamentais inatos mais flexíveis. A questão é compreender em qual dos modelos apresentados acima se encontra a moralidade. Uma possibilidade é que ela esteja mais próxima do comportamento de corvos para quebrar nozes, onde ainda que possa ser influenciada por inclinações sociais naturais, teria como elemento distintivo características não inatas. Outra alternativa é a de ser correlata com o hermafrodismo do gudião-azul, onde apresentaria um número 
fixo de variantes distintas influenciadas uniformemente pelo ambiente. Caso se assemelhe ao cântico mimético do estorninho, então estaria relacionada a mecanismos instintivos cuja função específica é imputar mérito moral a comportamentos sociais, ainda que seu conteúdo possa variar. Conforme Greene (2013), caso aspectos naturais sejam aplicados à moralidade, então ela deverá ser modular e possuir um desenvolvimento uniforme. Seguindo os diferentes modos de inatismo apresentados pelas ciências naturais, defendo que o fenômeno moral poderá ser considerado inato caso ao menos uma das características apresentadas acima se aplique aos comportamentos que o compõe.

[...] a moralidade é um dispositivo para permitir a cooperação [...] é uma coleção de dispositivos, um conjunto de capacidades psicológicas e disposições que juntas promovem e estabilizam o comportamento cooperativo ${ }^{7}$ (GREENE, 2013, p. 61 - minha tradução).

Darwin (1981) defende que a aptidão de determinadas espécies para desenvolverem os vínculos afetivos que as inclinam ao convívio social se deve aos mecanismos naturais da empatia e dos instintos sociais presentes nas mesmas. Em outras palavras, eles são mecanismos psicobiológicos que caracterizam um sistema instintivo geral de aprendizagem associados à composição genética de espécies que vivem em grupo. $O$ ponto a ser investigado acerca do inatismo moral se converge à possibilidade de apresentar a existência de princípios comportamentais que se desenvolveram a partir dessa constituição natural, a fim de compreender se desempenham alguma função específica relativa à moralidade. Dando continuidade a esta questão, retomarei sob uma ótica evolucionista dois conceitos tradicionais dentro das discussões acerca do fenômeno moral, a saber, a utilidade e a veracidade.

\section{Mecanismos psicobiológicos e o princípio da utilidade}

A utilidade é regularmente considerada como valorosa, seja com relação a condutas quanto a objetos. Hume (2004) defende que este princípio confere mérito moral a comportamentos sociais. Segundo o autor, do mesmo modo que ela é associada ao elogio, seu oposto está relacionado a críticas. Por exemplo, as portas de um edifício se tornam inúteis se forem muito pequenas e impossibilitarem a passagem dos sujeitos. A desaprovação está associada a sua perda de funcionalidade e consequente inutilidade. A reação emocional que

7 [...] morality is a device for enabling cooperation [...] is a collection of devices, a suite of psychological capacities and dispositions that together promote and stabilize cooperative behavior (GREENE, 2013, p.61). 
segue é associada à raiva ou indignação direcionadas ao engenheiro ou arquiteto responsável pela obra.

No que tange a comportamentos sociais, ações motivadas por emoções positivas são costumeiramente dignas de apreço. Em outras palavras, uma conduta pautada por intensões legítimas tende a ser mais apreciada que suas consequências concretas ou acidentais. Contudo, o mérito destas atitudes é ainda maior caso se mostrem úteis e contribuam com o bem-estar social, intensificando a resposta emocional positiva dos demais membros da comunidade. O comportamento de mamíferos encontrada na natureza é essencialmente simétrica e norteada por uma divisão de trabalho fundamentada em exigências recíprocas estabelecidas por vínculos afetivos ${ }^{8}$. Devido a esta forma de organização social emoções como raiva, nojo, culpa e vergonha são normalmente sentidas como uma resposta inibidora a comportamentos nocivos ao grupo. Desta forma, um princípio que opere de maneira a influenciar estas emoções tenderá a exercer influência no comportamento social.

E se os princípios [...] são capazes, em muitas ocasiões, de influenciar nossas ações, eles devem ter em todos os momentos alguma autoridade sobre nossos sentimentos 9 , fazendo-nos aprovar em geral o que é útil para a sociedade e censurar o que é perigoso ou nocivo (HUME, 2004, p. 294).

A leitura proposta é a de que há uma relação entre o princípio da utilidade e os mecanismos psicobiológicos presentes em mamíferos sociais. Ações que despertam prazer são instintivamente apreendidas pelo sujeito como boas, da mesma forma que atitudes que lhe infligem dor causam uma apreensão oposta. Nesse sentido, um ato agradará devido ao benefício que traz e o consequente prazer que desperta e vice-versa. Comportamentos sociais como a aversão a falsidade ou ao engodo distinguem-se de outros precisamente por sua utilidade na manutenção da harmonia do grupo. O ponto que defendo é que isso ocorre dado à maneira como mecanismos

8 Conforme Schleidt e Shalter (2003), vínculos afetivos entre seres humanos e canídeos foram potencializados durante o processo evolutivo devido à existência de mecanismos psicobiológicos similares de socialização. Portanto, é pertinente o uso de lobos como um caso exemplar para ilustrar o comportamento de mamíferos sociais. Mech (1999) propõe a hipótese de relações de parentesco baseadas em emoções para explicar a dinâmica social dos lobos. Em outras palavras, a hierarquia da alcateia é definida por uma relação simétrica entre seus membros a partir dos vínculos afetivos estabelecidos entre eles. Por este motivo, a terminologia alfa para designar os líderes foi substituída por casal procriador. Isso ressalta a inexistência de uma hierarquia inflexível com dominação baseada na força e reforça o vínculo parental e a dinâmica social de divisão de trabalho que de fato existe dentro da alcateia.

9 Conforme Sinhababu (2017) o conceito de sentimento em Hume é correlacionado com o que se entende contemporaneamente como emoções, a saber, reações dotadas de qualidades fenomenológicas únicas. 
psicobiológicos evoluíram em determinados mamíferos, propiciando certa convergência entre interesses particulares e sociais com base no prazer ou dor que despertam no sujeito.

Uma simples convergência de interesses baseada na empatia ${ }^{10}$ é apontada por Hume (2004) como insuficiente para explicar o comportamento moral. De fato, toda vez que vontades individuais e exigências sociais estiverem alinhadas haverá maior intensidade nas emoções sentidas e a distinção entre bom e ruim será mais vivaz. Contudo, há casos em que as motivações pessoais são contrárias aos interesses sociais, porém o que é verificado na natureza é que o zelo pelo grupo tende a permanecer ${ }^{11}$. Caso a força motriz da dinâmica social de mamíferos fosse uma tendência egoísta, então situações como essa jamais seriam encontradas na natureza. Todavia, este argumento ainda não esclarece em que sentido a utilidade poderia consistir no princípio de distinção entre comportamentos sociais e morais e nem como influenciaria reações emocionais baseadas em vínculos afetivos a permanecerem as mesmas diante de interesses opostos.

Da apresentação de evidências de que comportamentos sociais não são intrinsecamente motivados por interesses egoístas não decorre que se possa necessariamente auferir a eles uma inclinação altruísta. É plausível o argumento de que a motivação de ações direcionadas a preservação do bemestar social não esteja numa agradabilidade natural pelo que é útil. Entretanto, Hume (2004, p. 285-86) ressalta que "a utilidade é apenas uma tendência para certo fim, e seria contraditório supor que alguma coisa agrade enquanto meio para certo fim se esse próprio fim não nos afeta de modo algum". O que decorre dessa posição humeana é que o autor de uma atitude útil à promoção do convívio social recebe a aprovação dos demais membros do grupo. Sob uma ótica evolucionista, é coerente colocar que mecanismos psicobiológicos atuem sobre o princípio da utilidade e consistam no norte que direciona

10 Chamo a atenção para a inversão conceitual realizada na segunda metade do século $X X$, onde passou a ser denominada empatia o que até então se chamara simpatia. Embora historiadores intelectuais ainda utilizem o termo simpatia, darei preferência ao uso da empatia, posto que é utilizado dentro das discussões contemporâneas sobre o tema. 0 leitor que desejar uma discussão completa acerca desta revisão conceitual poderá encontra-la em Wispé (1986).

11 Fessler e Gervais (2010) relataram comportamentos de aversão ao engodo e ações de forte engajamento social em primatas. Mesmo considerando a plausibilidade da hipótese de que uma repulsa à perda de recursos próprios em prol do grupo e uma possivel inadequação às normas sociais possam contribuir para a economia energética do sujeito, este não foi o comportamento padrão observado. Pelo contrário, as observações reforçam a tese de que atitudes pró-sociais foram selecionadas durante 0 processo evolutivo destas espécies em virtude de sua utilidade e função adaptativa. Os pesquisadores sustentam que a inclinação do macaco prego (Cebus apella) em demonstrar agrado por regras de equidade semelhante à vista em seres humanos, sugere um traço comportamental já presente no ancestral em comum destas espécies há cerca de 35 milhões de anos. 
mamíferos sociais a sentirem prazer como resultado de ações que contribuam significativamente com a harmonia do seu grupo. Nesse sentido, a utilidade pode a ser compreendida como um princípio comportamental capaz de intensificar repostas emocionais em direção a comportamentos socialmente relevantes.

Dizer que nossas ações motivadas não se conformam, em geral, a princípios utilitários não significa negar que eles devam se conformar. Pode-se sustentar que é somente quando eles o fazem que nós os consideramos virtuosos (AYER, 2003, p.113).

A inteligibilidade emocional que pauta reações emocionais de aprovação e censura relativas a dinâmicas sociais de pequenos grupos tem como pedra fundamental mecanismos psicobiológicos. Acrescenta-se que, quanto maior a relação de contiguidade entre os integrantes de uma comunidade, mais harmoniosas serão as normas que circunscrevem seu convívio. Isso ocorre porque na medida em que a capacidade de compreender e reagir às emoções alheias se torna mais precisa, mais coesas serão a convivência e as ações do grupo. Considerando a importância deste tipo de convívio na sobrevivência de mamíferos sociais, é admissível considerar que o princípio da utilidade se moldou como uma adaptação funcional de contribuição à regulação social.

Processos empáticos consistem numa capacidade essencial ao estabelecimento de relações sociais pautadas por vínculos afetivos. Segundo Darwin (1981, p.62-63 - minha tradução) a empatia “[...] forma uma parte essencial dos instintos sociais, sendo de fato sua pedra fundamental ${ }^{12}$ ". Por sua vez, reações instintivas desta natureza tendem a ser mais duradouras do que motivações particulares, como o desejo sexual. Instintos sociais inclinam determinados mamíferos a comportamentos de grupo ao guiar o interesse do sujeito em direção ao bem-estar dos seus companheiros mais próximos.

[...] esses princípios de humanidade e simpatia enraízam-se tão profundamente em todos os nossos sentimentos e exercem sobre eles uma influência tão poderosa que os levam a provocar os mais enérgicos aplausos e censuras (HUME, 2004, p. 300).

É verdade que ele concede importância a processos cognitivos, no sentido de que o exercício da razão operaria no alargamento da sociabilidade natural para além das fronteiras da própria comunidade. De fato, a empatia também pode ser compreendida em um nível mais complexo como uma capacidade cognitiva para tomar o ponto de vista de outro ser. Contudo,

12 [...] forms an essential part of the social instinct, and is indeed its foundation-stone (DARWIN, 1981, p. $62-63)$. 
reflexões do entendimento são incapazes de engendrar no sujeito um interesse legítimo pelo bem-estar alheio, caso não exista em sua natureza os mecanismos psicobiológicos que o inclinam a formação de vínculos afetivos. Da mesma forma, embora processos empáticos possam desempenhar funções complexas, sua característica essencial está na propensão não cognitiva de sincretizar as emoções de dois ou mais sujeitos.

Tal sistema incita o observador a ressoar com o estado de outro sujeito, com o observador ativando representações e associando respostas autônomas e somáticas que derivam do alvo observado - isto é, um tipo de mapeamento inverso $^{13}$ (DECETY E JACKSON, 2006, p. 78 - minha tradução).

No início do artigo foi apresentado como emoções subjazem ações de aprovação e censura morais. Conforme Hume (2004, p. 298), “o intercâmbio de sentimentos na vida e convivência sociais faz-nos estabelecer certo padrão geral e inalterável com base no qual aprovamos e desaprovamos os caracteres e costumes". Ora, não há concepção teórica de certo e errado que despertará mais interesse no sujeito pelo bem-estar de seus companheiros do que a vinculação afetiva que enlaça tais relações. É importante salientar aqui que do elemento intersubjetivo presente neste tipo de vínculo não decorre que os princípios que o regulam não possam ser em alguma medida universais. $\mathrm{O}$ que se está defendendo é que mecanismos psicobiológicos associados ao princípio da utilidade conferem força moral a comportamentos sociais e mantém coesa a vida em grupo.

A intensidade das exigências recíprocas presentes na dinâmica social de grupos tende a ganhar mais força na medida em que os laços afetivos entre os membros se estreitam. Hume (2004, p. 299) atesta que "[...] a censura ou aprovação que daí decorrem adquirirão proporcionalmente um maior vigor". Desta forma, quanto mais próxima for à relação entre seus integrantes, maior será o apreço conferido a ações úteis e mais intensas serão as emoções negativas dirigidas a comportamentos socialmente nocivos. Conformo colocado por Prinz (2006), a base do mérito conferido a atitudes socialmente relevantes tem como base reações emocionais associadas à raiva, nojo, culpa e vergonha. Por sua vez, Hume (2004) acrescenta que a utilidade destes atos é o principal fundamento do mérito moral que lhe conferimos. O papel desempenhado pelo princípio da utilidade é o de direcionar estar emoções e qualificar as ações, sendo o critério de distinção entre o comportamento moral e outras formas de interação social.

${ }^{13}$ Such a system prompts the observer to resonate with the state of another individual, with the observer activating the motor representations and associated autonomic and somatic responses that stem from the observed target-that is, a sort of inverse mapping (DECETY E JACKSON, 2006, p. 78). 
A maioria dos atos ou caracteres que nós aprovamos são úteis para a sociedade, ou tendem a produzir o bem da humanidade. É devido a sua "utilidade" que nós aprovamos a justiça, a obediência à lei, fidelidade ou confiança [...] assim como a generosidade, caridade e moderação. Todas estas características contribuem para o bem-estar da humanidade, sendo por isso que temos esses sentimentos de aprovação, do modo como o temos, para com eles ${ }^{14}$ (STROUD, 1977, p. $194-$ minha tradução).

O princípio da utilidade inclina e intensifica as reações emocionais de mamíferos sociais relativas à aprovação ou censura de ações socialmente relevantes. Mediante conclusões amparadas na observação de constâncias comportamentais, Hume afirma que "[...] a tendência útil das virtudes sociais não nos motiva em vista de quaisquer considerações de interesse próprio, mas tem uma influência muito mais ampla e universal" (2004, p. 300). O argumento humeano sustenta que ações úteis agradam universalmente devido a sua tendência em promover a harmonia social. Disso decorre que a estima do grupo com relação aos sujeitos que realizam tais atos será maior e as emoções serão sentidas por eles com mais vivacidade. Conforme atesta Hume (2004), não há possibilidade de algo agradar enquanto meio para um fim se este não desperta no sujeito nenhum interesse.

Dentro de uma ótica evolucionista, caso a força motriz dos princípios que regem o comportamento social fosse negativa, então a tendência seria a autodestruição e nenhuma espécie que estivesse naturalmente inclinada a viver em grupo teria sobrevivido. É um princípio forte da natureza a busca por maximizar o prazer e evitar a dor. Devido aos mecanismos psicobiológicos presentes em espécies sociais, tal princípio os inclina a ter um interesse legítimo por atitudes que sejam úteis e beneficiem o convívio em grupo. Considerando que os integrantes de uma comunidade não são indiferentes ao bem-estar dos demais membros, caso nenhuma situação extraordinária os levem a romper tais vínculos, eles sentirão prazer em realizar ações que contribuam com o grupo e dor com relação a comportamentos opostos. Neste sentido, da afeição natural por ações socialmente úteis surge universalmente a inclinação de distinguir entre quem é um bom membro do grupo de seu oposto.

O que se impõe como "fim" contido na natureza do todo enquanto tal é a sua preservação como sistema, estando o preservar-se através da mudança já contido na condição do processo diferenciador enquanto processo constitutivo.

14 "Most of the acts or characters we approve of are useful to society, or tend to produce the good of mankind. It is because of their 'utility' that we approve of justice, obedience to law, fidelity or trustworthiness, and allegiance, as well as generosity, charity and moderation. All of these characteristics contribute to the well-being of mankind, and that is why we feel the sentiments of approbation towards them that we do" (STROUD, 1977, p.194). 
O todo o ser dado na relação todo-parte assim pensada deixaria de sê-lo e sua diferenciação deixaria de ser constitutiva, caso não conduzisse à sua autopreservação (REGNER, 1995, p. 9).

Pesquisas em etologia colocam a dinâmica social que pauta a vida em pequenos grupos como um sistema de exigências sincréticas onde a pressão para seguir as regras de convivência tem como base disposições emocionais influenciadas por mecanismos psicobiológicos. Desse modo, subjaz ao comportamento normativo encontrado nestas comunidades emoções como raiva, nojo, culpa e vergonha. O força coercitiva destas exigências está associada à intensidade dos vínculos afetivos que sustentam estas relações. Analisada por este espectro, as raízes da moralidade não estão num conjunto específico de regras da ação, mas em mecanismos de normatização naturais de onde se origina o princípio da veracidade como um qualificador moral universal, dado a sua grande utilidade na manutenção destas relações. Ora, quanto mais verazes forem os sujeitos menor será o gasto energético com disputas internas e maior será sua capacidade de agir com coesão diante de perigos externos. A próxima sessão deste artigo se destina exatamente a realizar uma leitura do princípio da veracidade a partir de uma ótica evolucionista.

\subsection{Processo evolutivo e o princípio da veracidade}

O ponto central desta sessão é o de compreender qual o significado de veracidade dentro de dinâmicas sociais pautadas por exigências emocionais sincréticas. Em linhas gerais, ser veraz está relacionado com agir de maneira à constantemente comunicar as próprias intensões com honestidade e clareza. Chamo a atenção que o elemento da veracidade ultrapassa os limites do discurso, sendo que a linguagem corporal comunica intenções com tanta precisão quanto outras formas de comunicação. Hume (2001) demonstra interesse por qualidades comportamentais desta natureza, colocando que apenas em virtude das sensações de prazer e dor que elas se configuram como disposições para as ações. Neste sentido, o sujeito veraz não é meramente motivado a comunicar seus desejos com honestidade pela vontade de ser bem quisto ou se mostrar confiável. Pelo contrário, sua motivação está no desconforto que enganar alguém com quem nutre laços afetivos causa e em evitar esta sensação ruim, da qual derivam emoções como culpa e vergonha. Agir com veracidade está associado à inclinação por uma consideração instintiva pelos membros do grupo, que por sua vez reconhecem esse sujeito como um bom membro da comunidade. Portanto, agir com veracidade se configura num comportamento útil ao convívio social. 
Essa suposição se torna necessariamente uma certeza quando descobrimos que a maior parte dessas qualidades que naturalmente aprovamos tem de fato essa tendência, e tornam os homens bons membros da sociedade; ao passo que as qualidades que naturalmente desaprovamos têm uma tendência contrária, e tornam qualquer relacionamento com a pessoa perigoso ou desagradável (HUME, 2001, p. 617).

A questão relevante é a de compreender em que sentido o princípio da veracidade está relacionado ao comportamento moral. É plausível considerar que a ação veraz está vinculada com a apreensão do que é um companheiro confiável e, consequentemente, um bom membro do grupo. Considerando uma dinâmica social pautada por exigências emocionais sincréticas, os comportamentos dos membros são limitados e influenciados pelo que cada um demanda do outro reciprocamente. Ainda que o espaço de manobra natural passa permitir que ajam de maneira diferente, as pressões emocionais inibem esse comportamento e restringem a liberdade dos sujeitos, de modo que a ação de cada um esteja em conformidade com o que esperam uns dos outros. Um bom membro do grupo se caracteriza exatamente por agir conforme o que é esperado pela comunidade, a saber, sem enganar ou trair seus companheiros.

Todo membro do grupo está suscetível à aprovação ou censura de seus companheiros caso suas atitudes destoem do que lhe é esperado. A censura é expressa por emoções como raiva e nojo, podendo inclusive incitar os integrantes da comunidade a expulsar o transgressor. Da mesma forma que há reações agressivas direcionadas a terceiros, reações de culpa e vergonha tendem a surgir no sujeito toda vez que ele falhar com as expectativas alheias. Dessa maneira, caso os laços afetivos que unem a comunidade não sejam sólidos, a força inibidora das emoções que atuam nestas relações sociais é enfraquecida, assim como a eficácia da aprovação ou censura alheias.

Exigências sincréticas constituem a base das normatividade encontrada nas dinâmicas de grupo apresentadas mamíferos sociais e sua força de constrangimento também está associada à existência de uma penalidade para a transgressão das regras da comunidade. Considerando a utilidade como potencializador da relevância social de determinadas ações, ela também constitui um princípio que direciona as emoções e as confere força de aprovação ou censura morais. Segundo Prinz (2006), as emoções socialmente relevantes que subjazem estas sansões são principalmente raiva, nojo, culpa e vergonha. Greene (2013) argumenta que mesmo em casos de discordância ou disputa, o sujeito não busca simplesmente se retirar do grupo com o qual convive. Pelo contrário, a tendência é mostrar aos demais integrantes do grupo que as exigências são injustas ou equivocadas, inclusive apresentando esforços para mostrar o que considera necessário mudar. 
Os mecanismos psicobiológicos propiciam inteligibilidade às emoções que, por sua vez, adquirem intensidade e direcionamento mediante a utilidade ao qual está vinculado o princípio da veracidade. Mesmo em casos de insatisfação perante as regras sociais, o sujeito ainda atua dentro do diapasão propiciado por esta estrutura natural. Nestas situações, não há um rompimento da vinculação afetiva e sim um redirecionamento das emoções sentidas como resposta a determinadas ações. O enraizamento social da moralidade se mantém mesmo quando ocorre divergência entre os membros do grupo. A diferença entre máximas pessoais e normas morais estaria no fato de que a segunda resulta da maneira como se desenvolveram as relações sociais ao longo do processo evolutivo.

A perspectiva acerca do fenômeno moral apresentada neste artigo não coloca a normatividade numa sociedade sem forma, mas na natureza dos sujeitos que a compõe. A investigação da aprovação e censura morais são direcionadas a compreensão da base dos comportamentos dos sujeitos que integram determinados grupos. Com relação às características sociais naturais, ressalto que a princípio não parece haver valores únicos dos quais se possa partir e nem para aos quais seja possível se referir. Essa objeção ganha maior força se vista a partir da relação entre o princípio de veracidade com a concepção de quando um sujeito é considerado bom. Neste caso, a noção de ser bom está intrinsecamente vinculada a de ser veraz que, por sua vez, está conectada ao princípio da utilidade com base em mecanismos psicobiológicos.

[...] as distinções morais surgem, em grande parte, da tendência das qualidades e caracteres para promover os interesses da sociedade e é nossa consideração por esse interesse que faz com que as aprovemos ou desaprovemos (HUME, 2001, p.618).

A inclinação a sentir raiva, nojo, culpa e vergonha com relação a si ou a terceiros sempre que há uma transgressão na norma existente no grupo está vinculada ao princípio da utilidade e aos mecanismos psicobiológicos. Afinal, caso o sujeito reaja emocionalmente quando ele próprio desapontar seus companheiros, ele agirá da mesma forma quando outro integrante da comunidade atuar da mesma forma. A princípio da veracidade se traduz no comportamento de agir com transparência para com o sistema normativo do grupo, sendo que todo membro que seguir as regras é apreendido instintivamente pelos demais como um bom companheiro.

O próximo passo é identificar em que medida disposições naturais e construções culturais influenciam o princípio da veracidade e a concepção do que é ser bom. Um caso exemplar de construção cultural é o da religião. Por exemplo, o Cristianismo apresenta sua normatividade a partir dos 
mandamentos divinos. A estrutura social cristã é vertical ${ }^{15}$ e a distinção moral está pautada pelas exigências comportamentais feitas por Deus para com seus seguidores. A norma moral se encontra sustentada num ato de fé, ao qual atitudes de aceitação verazes estão no cerne das exigências superiores. $O$ questionamento que surge é se dinâmicas sociais verticais são consideradas benéficas por seus seguidores porque isso lhes é imposto ou se eles a integram porque as apreendem como boas. O primeiro caso apresenta uma estrutura ditatorial, enquanto no segundo a veracidade associada a ser bom é independente de qualquer autoridade superior. Neste último caso a normatividade apresenta uma horizontalidade inerente à encontrada no comportamento de mamíferos sociais ${ }^{16}$.

No caso de seres humanos, a verticalidade encontrada em organizações sociais artificiais confere grande relatividade à noção de ser bom. O espaço de manobra da espécie é extremamente amplo, possibilitando inclusive que comportamentos autodestrutivos sejam considerados bons por autoridades específicas. Contudo, ainda que grupos com deste tipo possam existir, a história natural mostra que eles não constituem numa característica dominante da espécie. Afinal, caso tivessem sido predominantes os seres humanos não seriam bem-sucedidos em se adaptar, sobreviver e povoar todo o planeta. Darwin (1981) ressalta que a normatividade dos comportamentos sociais encontrados na natureza têm como ponto em comum sua utilidade na manutenção da harmonia do grupo. Isso acrescenta peso à hipótese de que a veracidade que subjaz a apreensão do que significa ser bom em mamíferos sociais tem como universalidade sua tendência a autopreservação.

Darwin (1981) sustenta que a seleção natural necessariamente atua nas diferentes formas de vida as tornando mais adaptadas ao ambiente em que habitam. A inclinação a autopreservação opera nas características fisiológicas e comportamentais de modo a potencializar a sobrevivência das espécies dotadas de maior aptidão. Regner defende que esta perspectiva abarca "uma visão de natureza como totalidade sistêmica, tendendo à autopreservação [...] através das interações e modificações das forças que a compõe" (1995, p.364). Portanto, a seleção natural consiste na maximização das adaptações

15 Sistemas sociais deste tipo tem como característica uma normatividade social colocada verticalmente de cima para baixo. Na natureza é possível encontrar comportamentos semelhantes, sendo que Michener (1974) descreve a hierarquia das abelhas dentro destes termos. Contudo, a universalidade do comportamento social em insetos ocorre devido a seu espaço de manobra restrito e não por uma consideração legítima pelas normas sociais.

${ }^{16}$ Mech (1999) relata que lobos apresentam um comportamento social de divisão de tarefas em que nem mesmo os líderes se encontram acima das regras que regem o convívio em grupo. Ainda que exista uma hierarquia entre seus membros, a dominação não é realizada mediante a força, mas exercida por vínculos de parentesco associados à eficiência na liderança. 
subjacentes às diferentes formas de vida, potencializando as qualidades vantajosas e eliminando as nocivas. Considerando que a utilidade e veracidade se encontram no primeiro grupo, a questão está em verificar se eles podem ser compreendidas como princípios comportamentais presentes em mamíferos sociais devido a sua função adaptativa.

O significado de ser bom pode variar entre diferentes grupos, mas caso sua força motriz fosse autodestrutiva, nenhuma dessas espécies teria sobrevivido. A universalidade do prazer que resulta de ações úteis à comunidade e sua consequente contribuição ao convívio entre seus membros foi essencial à sobrevivência de mamíferos sociais. Dessa característica se desenvolveram mecanismos psicológicos que conferem maior uniformidade de comportamento dentro de cada espécie. O fator que direciona as emoções e as confere intensidade para incitar ou inibir determinadas ações está nos princípios da utilidade e veracidade, aos quais a noção de ser bom está intrinsecamente vinculada. Comportamentos úteis realizados com veracidade granjeiam ao seu autor admiração e confiança de seus companheiros, que o percebem como um bom membro do grupo. Da mesma forma, atitudes autocentradas despertarão raiva em seus companheiros e culpa ou vergonha em quem realizou a ação. O ponto final está em explicar se os princípios da utilidade e veracidade podem ser transmitidos hereditariamente, a fim de compreender se estão presentes no fenômeno moral devido a um processo geral de aprendizagem ou se evoluíram para desempenhar essa função específica.

\section{Comportamentos morais inatos}

O princípio da utilidade é a pedra de toque que distingue comportamentos morais dos meramente sociais, sendo que o princípio da veracidade está vinculado unicamente a ações do primeiro tipo. Construções culturais e aspectos ambientais influenciam na capacidade e forma com que vínculos afetivos são estabelecidos e no tipo de ação que receberá aprovação ou censura. Por exemplo, é possível perceber essa influência mesmo em estruturas sociais verticais, como a religião ou os nacionalismos extremos. $\mathrm{O}$ ponto que defendo é que nesses casos ocorre um processo semelhante ao que impele pulgas a realizarem acrobacias no circo. Em outras palavras, condenar alguém por sua crença, sexualidade ou gênero não é um comportamento natural. Pelo contrário, constitui numa disfunção de uma adaptação comportamental que inclina mamíferos sociais a aprovar ou condenar com veemência ações que o grupo apreende como socialmente relevantes.

A maneira como mecanismos psicobiológicos evoluíram em mamíferos sociais os moldou a não serem indiferentes ao prazer e dor de seus 
companheiros. O interesse amplo pelo bem-estar do grupo associado ao princípio da utilidade, do qual comportamentos verazes subjazem a noção de ser bom inerente às estruturas sociais encontradas nessas espécies, estão na gênese do fenômeno moral. É verdade que diferentes espécies de mamíferos sociais possuirão distinções comportamentais entre si e são esperadas variações quanto ao grau de sensibilidade relativo à censura e aprovação morais. Todavia, em nenhuma destas espécies ocorre uma completa indiferença com relação à harmonia social. Ainda que de forma limitada, mesmo os sujeitos mais insensíveis estão inseridos na dinâmica de exigências sincréticas recíprocas e realizam distinções entre o que é socialmente bom ou ruim baseados em emoções.

A natureza social destas espécies as inclinam a sentirem prazer com ações benéficas ao seu grupo. É possível encontrar disputas hierárquicas entre primatas, mas mesmo rivais não negligenciam completamente a manutenção da estrutura social da comunidade, desde que seus interesses particulares não sejam totalmente negligenciados. Estrada (1991) observa que, mesmo nos casos de rivalidade interna mais extrema, os competidores não agridem os sujeitos com quem não possuem desavenças. Pelo contrário, eles mantém um interesse legítimo pelo bem-estar dos demais companheiros. Ainda que interesses particulares possam inclinar o sujeito a comportamentos egoístas, ações em prol do grupo tendem a prevalecer a longo prazo devido à característica duradoura dos instintos sociais. Embora exista variação relativa à intensidade dos vínculos afetivos e a consequente inclinação a preferir ações úteis à vida social, atitudes verazes e a valoração decorrente disso é um fato observado em diversos estudos etológicos ${ }^{17}$.

\footnotetext{
Nas espécies sociais como os ungulados, os canídeos, alguns felinos e particularmente nos primatas, a mãe inicia um longo processo de aprendizagem. Cada indivíduo com o qual o animal jovem entra em contato contribui para a sua educação. [...] Primatas jovens aprendem através de interações amistosas e agressivas na posição social que a sua mãe ocupa e, portanto, como devem conduzir relativamente a indivíduos acima ou abaixo dessa posição. (ESTRADA, 1991, p. 66)
}

Hume (2004) traz o exemplo de que mesmo um sujeito maligno não seria moralmente indiferente. Nesta passagem ocorre uma inversão entre o que é considerado moralmente bom ou ruim, visto que a harmonia social the

\footnotetext{
17 Estrada (1991) relata que no caso de mamíferos sociais como primatas e canídeos, os membros do grupo são responsáveis por instruir os filhotes mediante um longo processo de aprendizagem. Conforme Mech (1977) lobos aprendem as condutas sociais que thes são esperadas por meio de interações com os demais membros da alcateia. Ainda que a educação social não esteja gravada de forma rígida nos seus genótipos, a inclinação de ensinar a importância de ações transparentes no convívio social é considerada pelos autores como instintiva e inata.
} 
causaria desconforto e o sofrimento alheio seria apreendido prazerosamente. Numa leitura evolucionista, a tendência a autopreservação associada à vida em grupo presente em mamíferos sociais daria lugar a uma inclinação comportamental autodestrutiva. Dificilmente os membros destas espécies seriam bem sucedidos na transmissão genotípica e fenotípica associadas a este comportamento e ele tenderia a ser extinto pelo processo de seleção natural. Neste sentido, não é evolutivamente concebível que a perversidade e o egoísmo sejam o impulso predominante no comportamento destes animais.

A humanidade como um todo se assemelha tanto ao princípio do Bem que, quando nossas disposições não estão corrompidas pelo interesse, pelo ressentimento ou pela inveja, estamos sempre inclinados, pela nossa filantropia natural, a dar preferência à felicidade da sociedade e, consequentemente, à virtude, mais do que a seu oposto (HUME, 2004, p.95).

Entendo que a influência de elementos sociais e ambientais na moralidade é possível devido à existência destas características naturais. A atualização que proponho acerca da intuição humeana é a de que distinções morais baseadas em valores culturais são possíveis por causa dos mecanismos psicobiológicos que inclinam os sujeitos em direção a comportamentos socialmente úteis e ações verazes, de onde deriva o apreço por quem assim se constitui num bom membro do grupo. Enquanto o primeiro caso é correlato ao modo como pulgas realizam acrobacias no circo, o segundo se assemelha a sua capacidade inata de evitar produtos químicos nocivos. Neste sentido, tão basilares considero que são as raízes do fenômeno moral. O ponto é explicar como estas características são transmitidas entre gerações com base na constituição natural de mamíferos sociais.

Se a natureza não tivesse feito essa distinção com base na constituição original da mente, as palavras "vergonhoso", "estimável" e "odioso", "nobre" e "desprezível" não existiriam em nenhuma linguagem; e mesmo que os políticos viessem a inventar esses termos, jamais seriam capazes de torná-los inteligíveis ou fazê-los veicular alguma ideia aos ouvintes (HUME, 2004, p.279).

Atitudes motivadas por emoções não se dirigem universalmente a dinâmicas sociais. Emoções específicas surgem como motivadoras e responsivas perante ações socialmente relevantes, diferenciando estas relações de outras encontradas na natureza. Isto pode ser observado com clareza em mamíferos sociais e é anterior a qualquer estrutura cultural. De fato, Hume (2004) defende que a aprovação de condutas deste tipo é agradável ao ser humano e está associada à sua utilidade pública. O ponto que acrescento é o que dado à forma como mecanismos psicobiológicos se desenvolveram nestas espécies, o princípio da utilidade os inclina ao agrado pelo sujeito veraz e a sua consequente valoração instintiva como bom. 
Anteriormente foi apresentado como mamíferos sociais possuem forte inclinação ao convívio em grupo e como este comportamento é vantajoso à sua sobrevivência. Abrantes (2011) ressalta que é necessário à transmissão de padrões comportamentais a existência de um mecanismo que permita a difusão e estabilidade dessa variação, onde os descendentes diretos sejam mais próximos de seus antecessores que os demais membros da espécie. Essas características podem ser transmitidas por genótipo ou fenótipo ${ }^{18}$. É um ponto comum nas ciências naturais que fatores genéticos e ambientais estão implicados em transmissões fenotípicas. A questão pertinente com relação à moralidade consiste na busca de uma característica transmitida hereditariamente que tenha evoluído com a função específica de imputar mérito moral.

Brandon e Antonovics (1996) defendem que modificações induzidas parentalmente podem influenciar o comportamento e aumentar a similaridade pais-descendentes relativas a características específicas. A transmissão de fenótipos é definida por Mameli como “[...] a propriedade de características fenotípicas [...] para as quais há variação estável entre gerações, independentemente de essa variação ser causada geneticamente ou não ${ }^{19^{\prime}}$ (2004, p.36 - minha tradução). Considerando que o princípio da utilidade inclina determinadas espécies a comportamentos pró-sociais centrais a sua sobrevivência, é plausível colocar que ele seja transmitido da forma descrita acima. Afinal, ele influencia a dinâmica social do grupo e potencializa os benefícios da mútua proteção e assistência.

A natureza, se me for permitido personificar a atual preservação ou sobrevivência do mais apto, não se importa nada com as aparências, a menos que sejam úteis a qualquer ser. Ela pode agir sobre cada órgão interno, sobre cada sombra de diferença constitucional, sobre a inteira maquinaria da vida. $\mathrm{O}$ homem seleciona apenas para o seu próprio bem; a natureza, apenas para o bem do ser que cuida (DARWIN, 2004, p, 65).

O sincretismo emocional propiciado pela estrutura natural de mamíferos sociais subjaz a dinâmica de grupo encontrada ordinariamente nestas espécies. Defendo que isso abrange a posição de Hume (2004, p. 284) de que "dado que a experiência é o principal agente na formação das

\footnotetext{
18 Beiguelman (2008) coloca que fenótipos são utilizados na biologia tanto para indicar elementos específicos quanto conjuntos de características observáveis num sujeito. Dessa forma, a transmissão fenotípica pode estar associada a padrões de comportamento, sejam eles compreendidos de forma geral ou particular. Segundo o autor, em ambos os casos o fenótipo consiste no resultado da interação do genótipo com influências do ambiente.

19 "...] a property of phenotypic traits for which there is an intergenerational stable variation, independently of whether such variation is genetically-caused or not" (Mameli, 2004, p.36).
} 
associações de ideias, é impossível que qualquer associação consiga estabelecer-se e persistir em direta oposição a esse princípio". Dentro destas relações, ocada membros do grupo é constantemente alvo da aprovação e censura de seus companheiros. Sendo assim, o ato de distinguir entre ações boas e ruins com base em emoções deve ser comum a qualquer membro destas espécies.

Decety e Jackson (2006) entendem que mecanismos psicobiológicos possuem uma base genética que propicia um sincretismo entre as emoções de dois ou mais sujeitos. Tais características evoluíram de maneiras distintas entre as diferentes espécies ao longo do processo evolutivo. Essa variação é percebida desde a estrutura social rígida de insetos até o comportamento flexível de mamíferos, que inclusive possuem espaço de manobra amplo a ponto de o sujeito adulto sobreviver mesmo sem o grupo ${ }^{20}$. Entretanto, os vínculos afetivos inibem comportamentos autocentrados e os inclinam a agir conforme as regras da comunidade. O que se observa na dinâmica social destes animais é que uma ação não é apenas boa para um ou para o outro, mas que é apreendida como boa a aprovada conjuntamente por todo o grupo. Caso vista a partir dessa ótica natural, a moralidade tem como característica central uma aprovação coletiva instintiva que inibe comportamentos autocentrados ou autodestrutivos.

Ações úteis despertam afeição e seus autores recebem a aprovação dos demais integrantes da comunidade. Este é um fato que pode ser observado no comportamento ordinário de mamíferos sociais. Neste caso, uma atitude útil sempre converge em direção aos interesses coletivos. Ainda que sua análise seja restrita a seres humanos, Hume (2004, p. 284) aponta que "devem [...] ser os interesses dos que são beneficiados pelo caráter ou ação que recebe aprovação, o que nos leva a concluir que esses interesses [...] não nos são totalmente indiferentes". Numa visão evolucionista posterior, diria que a constituição natural de mamíferos sociais coloca estes interesses para além da esfera egoísta. O fator distintivo entre comportamentos sociais e morais dentro destas relações está no princípio da utilidade e da veracidade aos quais está intrinsecamente vinculada a noção de ser bom.

Apesar de ser um critério de distinção entre comportamentos morais e sociais, defendo que o princípio da utilidade, apesar de sua influência sobre

20 Segundo Mech (1997) não há evidência empírica que ateste um relação vantajosa entre a vida social dos lobos e sua eficiência de caça enquanto adultos. A vida dentro da alcateia é vantajosa especialmente para defender 0 território e evitar que outros animais roubem comida dos filhotes. $O$ autor defende que vínculos de parentesco baseados em emoções para explicar o comportamento social dos lobos, onde o hierarquia da alcateia não é definida pela força bruta, mas por exigências sincréticas pautadas por vínculos afetivos. 
mecanismos psicobiológicos, não constitui em si numa característica que torne a moral inata. Minha visão é que ele constitui um fenótipo adquirido mediante um sistema instintivo e geral de aprendizagem com base num condicionamento operacional. Mesmo ações egoístas podem ser úteis ao sujeito, sendo que o agrado coletivo pela utilidade depende da existência dos vínculos afetivos que pautam a vida de mamíferos sociais.

Por outro lado, o princípio da veracidade deriva de mecanismos psicobiológicos influenciados pelo princípio da utilidade e sua única funcionalidade é imputar mérito moral nos sujeitos que agem desta forma. Ele resulta de transmissão fenotípica e é essencial à apreensão do que é um bom membro do grupo de seu oposto. Defendo que é mediante o desenvolvimento do princípio comportamental da veracidade que comportamentos morais, entendidos como a inclinação emocional de imputar mérito a sujeitos com base em suas ações dentro do grupo, podem ser considerados como inatos. Em outras palavras, é a partir da natureza dessas relações que a moralidade pode ser considerada como um comportamento inato presente em mamíferos sociais.

\section{Conclusão}

O comportamento social em pequenos grupos é influenciado pelos mecanismos psicobiológicos da empatia e dos instintos sociais. Dada a capacidade destes animais de empatizar com a dor ou prazer de seus companheiros, uma ação socialmente benéfica para o grupo tende a causar uma sensação agradável e será experimentada como boa pelos membros do grupo. Tomada num escopo mais amplo, a distinção entre bom e ruim está baseada nas sensações de prazer e dor desses animais. Numa perspectiva evolutiva, caso a força motriz do comportamento social fosse negativa, então tenderia à autodestruição e nenhuma espécie que dependesse dessa característica para sobreviver seria bem-sucedida. Vinculada à afeição natural apresentada pelos mamíferos sociais em relação às ações que promovem a harmonia coletiva, está à inclinação instintiva de distinção entre o que é ou não um bom membro do grupo.

Mecanismos psicobiológicos conferem inteligibilidade às emoções, que por sua vez consistem na base de comportamentos sociais como proteção mútua, divisão de alimentos e trabalho, defesa e cuidado dos filhotes, dentre outros. É uma característica intrínseca desses comportamentos o princípio da veracidade, que consiste em um traço de caráter que traz grande contribuição para a harmonia social do grupo e sua consequente tendência à autopreservação. A seleção natural opera para preservar formas de vida 
vantajosas, potencializando características que tendem a sua preservação e eliminando as autodestrutivas.

O prazer decorrente do comportamento social depende dos mecanismos psicobiológicos para ser sentidos. Dessa forma, ações verazes inerentes à vida social de mamíferos tem a funcionalidade específica de conferir mérito moral aos sujeitos com base em seu comportamento social. O princípio da utilidade constitui um fenótipo adquirido por um sistema de aprendizagem instintivo e sua funcionalidade dentro do comportamento moral está em direcionar comportamentos à manutenção da harmonia social com base no prazer que desperta nos sujeitos. O princípio da veracidade também resulta da transmissão fenotípica, mas constitui numa tendência comportamental dirigida especificamente à função social de imputar o mérito moral, conferindo caráter inato a comportamentos dessa natureza.

\section{Referências Bibliográficas}

ABRANTES, P. C. Filosofia da Biologia. Porto Alegre: Editora Artmed, 2011.

AYER, A. J. Hume. São Paulo: Loyola, 2003.

BEIGUELMAN, B. A interpretação genética da variabilidade bumana. Ribeirão Preto: Editora SBG, 2008.

BLAIR, R. J. R. "A cognitive developmental approach to morality: Investigating the psychopath". In: Cognition, v.57, p.1-29, 1995.

BRANDON, R. N. e ANTONOVICS, J. "The coevolution of organism and environment". In: R. N Brandon (ed.) Concepts and Methods in Evolutionary Biology. Cambridge, MA: Cambridge University Press, 1996, p.161-178.

CLECKLEY, H. M. The mask of sanity: An attempt to reinterpret the so-called psychopathic personality. St Louis: The CV Mosby Company, 1941.

COWIE, F. What's within? Nativism reconsidered. Oxford: Oxford University Press, 1999.

DARWIN, C. The Descent of Man, and Selection in Relation to Sex. Princeton: Princeton University Press, 1981. - A origem das espécies. São Paulo: Ediouro, 2004.

DECETY, J. e JACKSON, P. L. "A Social-Neuroscience Perspective on Empathy". In: Current Directions in Psychological Science, v.15, p.54-58, 2004.

ESTRADA, A. Comportamiento animal: el caso de los primatas. México: Fondo de Cultura Económica, 1991. 
FESSLER, D. M. T. e GERVAIS M. "From whence the captains of our lives: Ultimate and phylogenetic perspectives on emotions in humans and other primates". In: Kappeler P. M. e Silk J. B. (eds.) Mind the Gap: Tracing the Origins of Human Universals. Heidelberg, HD: Springer, 2010, p.197-220.

GREENE, J. Moral Tribes: Emotion, Reason, and the Gap Between Us and Them. New York: Penguin Press, 2013.

HAUSBERGER, M., JENKINS, P. F. e KEENE, J. "Species specificity and mimicry in bird song: are they paradoxes? A re-evaluation of song mimicry in the European starling". In: Behaviour, v.117, p.53-81, 1991.

HUME, D. 2001. Tratado da natureza humana: uma tentativa de introduqir o método experimental de raciocínio nos assuntos morais. Traduzido por Débora Danowski. São Paulo: Unesp.

- Investigações sobre o entendimento bumano e sobre os princípios da moral. Traduzido por José Oscar de Almeida Marques. São Paulo: Unesp, 2004.

KELLEY, L., COE, R., MADDEN, J. e HEALY, S. "Vocal mimicry in songbirds". In: Animal Behavior, v.76, p.521-528, 2008.

MAMELI, M. "Nongenetic Selection and Nongenetic Inheritance". In: British Journal for the Philosophy of Science. v.55, p.35-71, 2004.

MARSH, K. E. Neuroendocrine Transduction of Social Cues in the Bluehead Wrasse, Thalassoma bifasciatum. Tese de doutorado. Raleigh, NC: North Carolina State University, 2007.

MECH, L. D. "Productivity, morality and population trends of wolves in northeastern Minnesota”. In: Journal of Mammalogy, v.58, p.559-574, 1977. .The arctic wolf: Ten years with the pack. Stillwater: Voyageur Press, 1997.

" "Alpha Status, Dominance, and Division of Labor in Wolf Packs". In: Canadian Journal of Zoology, v.77, p.1196-1203, 1999.

MICHENER C. D. The Social Behavior of the Bees: A Comparative Study. Cambridge: Harvard University Press, 1974.

PATRICK, C. J. "Emotion and psychopathy: Startling new insights". In: Psychophysiology, v.31, p.319-330, 1994.

PRINZ, J. "The Emotional Bases of Moral Judgements". In: Philosophical Explorations, v.9.1, p.29-43, 2006.

“Is morality innate?” In: W. Sinnott-Armstrong (ed.), Moral Psychology.

Oxford: Oxford University Press, 2008, p.1-34. 
REGNER, A. C. K. A natureza teleológica do princípio darwiniano de seleção natural. Tese de doutorado. Porto Alegre, RS: Universidade Federal do Rio Grande do Sul, 1995.

SCHLEIDT, W. M., Shalter, M. D. "Co-evolution of Humans and Canids, an Alternative View of Dog Domestication: Homo Homini Lupus?” In: Evolution and Cognition, v.9, p.57-72, 2003.

SINHABABU, N. Humean Nature. Oxford: Oxford University Press, 2017.

STROUD, B. Hume. London, EN: Routledge \& Kegan Paul, 1977.

WISPÉ, L. "The distinction between sympathy and empathy: to call forth a concept, a word is needed". In: Journal of Personality \& Social Psychology, v.50, p.314-321, 1986.

WHEATLEY, T. e HAIDT, J. "Hypnotically induced disgust makes moral judgments more severe". In: Psychological Science, v.16, p.780-784, 2005. 